\title{
Automatic Recognition of Gait Patterns in Human Motor Disorders using Machine Learning: A Review
}

\author{
Joana Figueiredo*1 · Cristina P. Santos ${ }^{1} \cdot J^{\prime}$ an C. Moreno ${ }^{2}$
}

$1 \quad{ }^{1}$ Center for MicroElectroMechnical Systems, University of Minho, Guimarães, Portugal

2 E-mail: id6003@alunos.uminho.pt; cristina@dei.uminho.pt

3 Tel.: +351-253-510-190; Fax: +351-253-510-189

4

$5 \quad{ }^{2}$ Neural Rehabilitation Group, Cajal Institute, Spanish National Research Council, Spain

6 E-mail: jose.pons@csic.es; jc.moreno@csic.es

8 * Corresponding author: Industrial Electronics Department, University of Minho, 4800-058 Guimarães, Portugal. E-mail:

9 id6003@alunos.uminho.pt; Tel.: +351-253-510-190

Abstract

12 Background: Automatic recognition of human movement is an effective strategy to assess abnormal gait 13 patterns. Machine learning approaches are mainly applied due to their ability to work with multidimensional 14 nonlinear features.

15 Purpose: This review aims to compare several machine learning algorithms employed for gait pattern 16 recognition in motor disorders using discriminant features extracted from gait dynamics. Additionally, this work 17 highlights procedures that improve gait recognition performance.

18 Methods: We conducted an electronic literature search on Web of Science, IEEE, and Scopus, using "human 19 recognition", "gait patterns", and "feature selection methods" as relevant keywords.

20 Results: Literature analysis showed that kernel principal component analysis and genetic algorithms are efficient at reducing dimensional features due to their ability to process nonlinear data and converge to global optimum. Comparative analysis of machine learning performance showed that support vector machines (SVMs) exhibited higher relative accuracy and proper generalization for new instances.

24 Conclusions: Automatic recognition by combining dimensional data reduction, cross-validation and normalization techniques with SVMs may offer an objective and rapid tool for investigating the subject's clinical status. Future directions comprise the real-time application of these tools to drive powered assistive devices in free-living conditions. 


\section{Introduction}

Walking is one of the most common human physical activities that can be performed in a variety of conditions and environments [1]. Analysis of human gait patterns can provide significant information related to the physical and neurological functions, and it may contribute to the diagnosis of human motor disorders in pathological conditions [2,3]. For these purposes, the human gait patterns need to be recognized, i.e., categorized according to the situation or clinical status of the analysed locomotor function.

Several studies have argued that automatic recognition of human gait patterns allows us to (i) conduct a quantitative and non-invasive diagnosis of locomotion by comparing the studied locomotor function to a

9 healthy-standard gait [1,4,5], (ii) indicate a subject-specific task for personalized gait training by automatically

10 adjusting assistance in accordance with the users' recognized motor function [6], (iii) plan future treatment according to the user's needs, i.e., according to the user's gait impairment previously recognized through automatic recognition methods $[1,4,5]$, and (iv) quantify and describe the progress of gait treatment by

13 comparing the user's gait patterns at baseline and follow-up moments [1,4,5]. Additionally, these automatic 14 systems for clinical gait analysis constitute an objective technique for massive manipulation of gait data, and 15 they are more quick and cost-effective than the conventional procedures usually used by clinicians $[1,7,8]$.

Various gait disorders have been investigated in the context of pattern recognition to improve initial diagnosis techniques. The injuries that often lead to gait disorders are stroke, spinal cord injury (SCI), Parkinson's disease (PD), cerebral palsy (CP), multiple sclerosis (ME), hip and knee osteoarthritis (OA), and age-related gait impairment. However, the current strategies that have been proposed for the automatic recognition of gait disorders still do not incorporate historical clinical information about the patient in diagnosis analysis [9]. In an attempt to improve the locomotor pattern of neurological injury patients, gait training procedures' have been developed, such as treadmills with or without body weight support, functional electrical stimulation, robotic assistive devices, and the use of virtual scenes that simulate walking in different environments $[6,10,11]$.

To conduct a more comprehensive and reliable recognition of human motor pattern, diverse types of gait dynamics, such as spatiotemporal, kinematic, kinetic and physiological indicators (e.g., electromyographical activity and pulse rate), may be considered since they distinctly describe locomotor function $[4,12,13]$. Most commonly, the monitoring of these parameters involves expensive but highly accurate systems, such as infrared 
cameras, optoelectronic systems and force plates [14,15]. As non-ambulatory devices, these sensory systems only operate in controlled environments, [16] and therefore, they have a difficult time analyzing consecutive gait cycles for long-term applications, especially in a free-walking scenario [17,18]. Consequently, current research has focused on the design and application of recognition tools that only use gait dynamics recorded by wearable sensory systems, such as force-contact sensors (e.g., footswitches and foot pressure insoles), accelerometers, gyroscopes, and inertial measurement units (IMUs) [19]. Recent technological advances make these sensors smaller, lighter in weight, easier to don and doff, and cheaper than external sensors. They also have good user compliance and a comparable performance to the external ones [17,20,21]. Furthermore, these measuring devices permit the extension of the recognition process to free-living conditions and foster a more time- and cost-effective categorization of human gait patterns than external devices. Ambulatory recognition with wearable sensors in free-walking environments can also introduce benefits by offering functional roboticoriented therapies[22-24]. Research groups tend to choose between external and wearable sensory systems at 13 an early stage, so this choice needs to be carefully considered as a function of the research interest of the study.

14 Considering the potential of automatic recognition and given its contribution to the gait rehabilitation field, 15 we have reviewed recent studies that employed machine learning algorithms in an offline setting to automatically recognize the clinical status of human locomotion. Our reasons for focusing our search on machine learning approaches are three-fold: (i) their generalized ability to the model the complex nonlinear relationships inherent to gait data; (ii) their aptitude to work with multidimensional data; and (iii) their ability to easily incorporate newly data in an attempt to improve prediction performance $[7,25,26]$. We reviewed studies that exclusively employed gait dynamics recorded from either external (e.g., force plates and motion analysis systems) or wearable (e.g., IMUs and instrumented shoes) sensory systems. We did not include studies that used features encoded as images. In fact, we only analysed studies that extracted features from biomechanical signals that describe the gait. We applied this selection criteria since we propose to disclose a walking recognition procedure that only depends on gait information that may be acquired from wearable sensors to take advantage of this sensory technology. In fact, there are wearable sensory solutions that can monitor the same biomechanical parameters those that are conventionally monitored by optoelectronic systems and force platforms. In contrast, studies that included image-specific features were not investigated given the limitation of the recognition process in the motion analysis laboratory. 
This review also provides a comparative analysis of various machine learning methods applied to locomotor

2 patterns classification according to their advantages and drawbacks exhibited in gait analysis. Moreover, we

3 highlight and review pre-processing procedures that are commonly applied before the classification process to

4 improve the performance of gait recognition. In the scope of this review, pre-processing procedures cover

5 methods for dimensional gait data reduction (feature selection methods), methods for cross-validation (CV) and

6 feature normalization. Based on the reviewed information, we identify a standard procedure for human walking

7 recognition using gait dynamics, and address the main search questions raised in this study: (i) What are the

8 most appropriate classification methods to recognize gait patterns using gait dynamics?; and, (ii) What are pre-

9 processing methods that improve the gait pattern recognition? To the best of the authors' knowledge, there are

10 no previous works on the state-of-the-art that address this comparative analysis; this analysis highlight strategies

11 that are capable of performing intelligent, accurate, rapid and cost-effective clinical gait analysis.

12 The schematic diagram depicted in Fig. 1 highlights the standard procedure for the recognition of human

13 gait patterns using gait dynamics, which involves the following stages: extraction of gait features from gait

14 dynamics; normalization of features; methods to select the most relevant features; classification stage; and,

15 evaluation of the recognition process. This diagram was elaborated in accordance with the surveyed contents,

16 and it consequently states the topics discussed in this review. Section 2 outlines the search strategy conducted

17 in this literature survey and the extracted data. Section 3 describes the mathematical principles and the

18 application of multivariate statistical approaches (used as feature selection methods) in gait recognition. Section

194 highlights and compares the most relevant studies that employed machine learning approaches for offline

20 walking recognition using gait dynamics. Section 5 systematizes strategies to improve the performance of gait

21 pattern recognition namely, feature normalization and cross-validation methods. Conclusions and future

22 directions are noted in Section 6. 


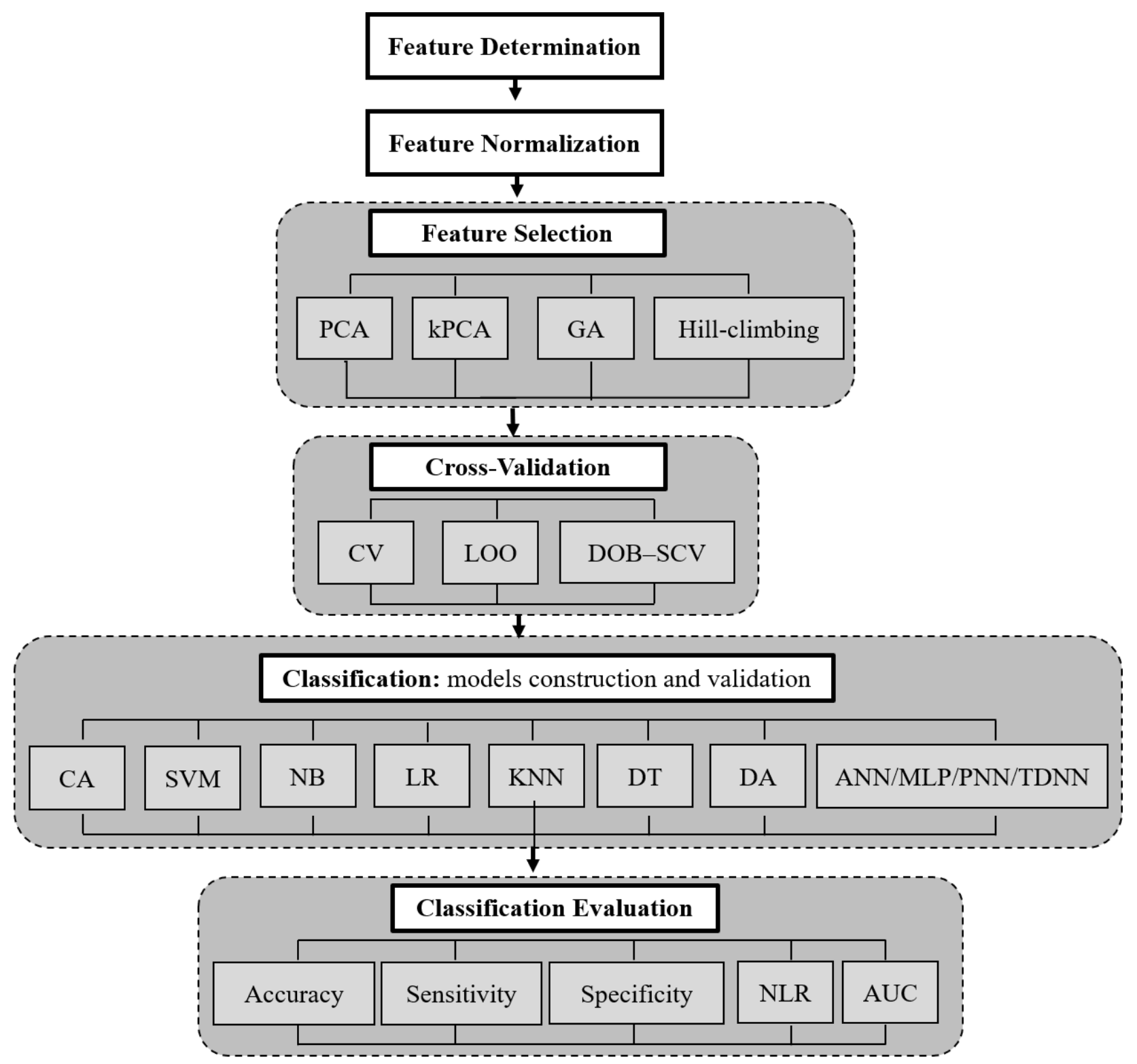

2 Fig. 1 Schematic diagram of a standard procedure implemented for gait recognition using gait dynamics. The acronyms used in this diagram correspond to the following: linear principal component analysis (PCA); kernel based-PCA (kPCA); genetic algorithm (GA); cross-validation scheme (CV); Leave-One-Out (LOO); distribution optimally balanced stratified CV (DOB-SCV); clustering analysis (CA); support vector machine (SVM); Naïve Bayes (NB); logistic regression (LR); K-nearest neighbors (KNN); decision tree (DT); discriminant analysis (DA); artificial neural networks (ANN); multilayer perceptron (MLP); probabilistic neural network (PNN); time delay neural network (TDNN); negative likelihood ratio (NLR); and area under the curve (AUC).

2 Methods

\subsection{Search Strategy}

10 We conducted a comprehensive electronic literature search in Web of Science, IEEE, and Scopus on studies

11 from 2000 onward. In this electronic search, we applied the following keywords: ["human recognition" OR

12 "human classification"] AND ["gait patterns" OR "locomotion"] AND ["impaired gait" OR "pathologic gait"]

13 AND ["offline"] AND ["feature selection methods"]. In addition, wildcard symbols, such as hyphens or inverted 
commas, were used to consider all possible variations of root words. The search was limited to titles and abstracts.

The papers identified in the initial search were included if they: (i) implemented machine learning approaches to distinguish between pathologic and physiologic locomotion (e.g., healthy/pathological gait and young/elderly subjects) or to recognize pathologic scenarios, such as fall risk and fatigue; (ii) only considered an offline recognition process; (iii) did not involve image-specific features acquired from ambulatory and/or non-ambulatory sensors; (iv) accomplished classification using normalized or non-normalized features extracted from biomechanical data on gait, such as spatiotemporal parameters, kinematics, kinetics and physiological indexes; (v) applied feature selection methods only as a pre-processing technique for the classification stage, (vi) were an original work; and, (vii) were written in English. Works that explored CV methods and other strategies to improve machine learning performance were also included. In addition, we did not impose constraints regarding sample size (number of subjects, number of trials, or number of strides) or the

13 dimension of the features dataset.

\section{4}

\subsection{Data Extraction}

One researcher (JF) selected the studies and extracted their relevant data. Four researchers analysed and checked the extracted information (CS, JF, JM, and JP). Two different tables were used to extract the data related to the application of feature selection methods (Table 1) and machine learning approaches (Table 2) in the recognition process of gait patterns. For Table 1, we extracted the following information regarding the application of feature selection methods: the study's identification; multivariate statistical approach; goal of dimensional reduction; dataset size and description of involved features; and main results obtained with and without (when available) the feature selection step. The data extracted in Table 2 included the study's identification, goal, number, gender and age of the participants, gait dynamics (description and dataset size, when available), involved feature selection, cross-validation and normalization methods (when available), applied machine learning algorithms, and main results. Additionally, we extracted data concerning the methodologies implemented in the included studies to improve recognition performance (Section 5).

All the information extracted from the selected studies served as the benchmark to broaden and discuss the concepts of the issues in question. A descriptive and comparative analysis was performed since the identified data were insufficient for a meta-analysis. 


\section{Feature Selection Methods}

Recent advances in sensory technologies for data acquisition (e.g., smaller, lighter in weight, and cheaper sensors) have contributed to an enormous increase in the number of empirical signals, which implies a priori selection of sufficient empirical quantities for the recognition of patterns [27]. Data reduction techniques based on parameters' selection from gait waveforms (e.g., peak values and magnitudes at specific gait cycle events) are popular due to their simplicity [28]. However, this methodology is often subjective and selects parameters that can highly be correlated [28]. Thus, methodologies for a proper feature selection have been proposed to improve classification performance (e.g., increase accuracy) $[7,29,30]$ by selecting the features that represent the maximal separation between classes [31,32] and providing faster and more cost-effective models [31,33]. These methodologies can be organized into three categories: filter methods (open-loop methods); wrapper methods (closed-loop methods); and, embedded methods (closed-loop methods) [31].

Filter methods work on the dataset without considering the classification algorithm. Subsequently, data analysis involves a heuristic criterion that only depends on inner data properties (e.g., distribution of values and correlation between features) [31,34]. These methods are computationally simple and prompt [31].

On the other hand, the wrapper methods use a heuristic criterion to evaluate the different subsets in accordance with the specific performance of a classifier. Therefore, to select the features, the wrapper methods consider the dataset and the classifier properties, tailoring this approach to a specific classification algorithm

18 [31,34]. These methods are less prone to a local minimum, although they exhibit the risk of over-fitting and are computationally intensive [31].

Embedded methods have the advantage that they include interaction with the classification model; however, at the same time, they are far less computationally expensive than wrapper methods [31].

As illustrated in Fig. 1, the feature selection methods commonly used in walking recognition are PCA and their derived kPCA (both filter methods), GA (wrapper method), and hill-climbing (embedded method) [34,35].

24 We describe these multivariate statistical approaches in Section 3.1 and disclose their application in recent works in Section 3.2.

\subsection{Multivariate Statistical Approaches and Optimization Techniques}

Different multivariate statistical approaches that facilitate the interpretation of data based on variance 
1 the optimal linear transformation that best represents the data in the least square sense [3], and thus, it does not

2 require the choice of any classifier. It yields a set of orthogonal bases in a new coordinate system and captures

3 the directions of maximum variance in the training data [3,36-38]. The dimensional reduction is performed by

4 keeping the first principal components (PCs), i.e., the values that retain the most variance of the data [3,29].

$5 \quad \mathrm{kPCA}$ is a dimensional reduction technique of nonlinear data that maps the input data into a higher-

6 dimensional feature space through a kernel function (e.g., linear, polynomial and radial basis function (RBF)

7 kernels) [36,39]. Then, PCA method is applied in the feature space to extract the PCs of gait features [36,39].

8 Recognition studies have demonstrated that polynomial kernel achieves the best performance than linear or RBF

9 kernels [36,40]. In addition, according to Liang and Lee [40], the data projections for even-degree polynomial

10 kernels, particularly 2-degree polynomials, tend to make the clusters linearly separable.

11 GA is a time-efficient optimization technique that searches the entire data space to find the best solution

12 inspired in the natural selection process in genetics [35,41,42]. First, it randomly creates the populations (data

13 to be processed). Then, in each iteration, GA only keeps the potential candidates that better optimize the cost

14 function defined according to selected classifier (wrapper method) for the next iteration [42,43]. These

15 populations can be processed by three genetic operators: selection, crossover, and mutation [44]. In this sense,

16 the data space is iteratively modified, and GA quickly converges to the global optimum solution $[35,42,44]$. GA

17 is also able of dealing with multivariable data space and nonlinear input-output interactions $[35,42,43,45]$.

18 Regarding the hill-climbing algorithm, it is a sequential feature selection algorithm that iteratively searches

19 the features that positively contribute to classification accuracy [46,47]. Hill-climbing uses each feature for an

20 initial classification, and based on the performance of this classification, the features are ranked from highest to

21 lowest $[47,48]$.

\subsection{Search Results and Discussion}

23 The feature selection methods noted in Section 3.1 have been used in the dimensional reduction of gait 24 parameters, and they constitute a relevant pre-processing method for gait pattern classification. Table 1 25 synthesises the purpose, features dataset and recognition results of the seven collected studies that applied 26 feature selection methodologies in offline gait pattern recognition. These studies are the outcome of the search 27 strategy carried out in this literature review, which considered studies published since the year 2000 that 
1 exclusively involved feature selection methods as pre-processing in machine learning approaches for

2 dimensional reduction of gait dynamics.

3 In the seven included studies, four works applied PCA [28,36,38,49], one study investigated kPCA [36], two

4 works implemented hill-climbing strategies [48,50], and the reaming study employed the GA method [44].

5 Nevertheless, all investigated works integrated distinct features datasets in terms of biomechanical parameters,

6 and sample size. This heterogeneity in the datasets demonstrates that the reviewed multivariate statistical

7 approaches can be applied to discriminate physiological, spatiotemporal, kinematic and kinetic parameters

8 independently of the number of input features. Moreover, such divergence compromises the comparison of the

9 impact obtained by dimensional reduction in offline recognition. Indeed, only one study [36] compared the

10 effects obtained in the classification process by two different feature selection methods namely, PCA and kPCA.

11 In general, Table 1 shows that the use of feature selection methods improves the accuracy of gait pattern

12 recognition compared to inclusion of the entire dataset. For instance, in one study [49], the accuracy grows from

$1358 \%$ to $95.8 \%$ due to proper identification of the relevant features for the classification by applying PCA.

14 Furthermore, Wu et al. [36] also showed that identification of the most relevant features by kPCA (17 features

15 against an original dataset of 36 features) augmented the classification accuracy from $85 \%$ (no dimensional

16 reduction) to $91 \%$ [36]. This behaviour results from the ability of dimensional reduction to create a compact set

17 of uncorrelated features that still characterize the original data without redundancy [47]. Nevertheless, two

18 studies $[38,50]$ reported similar classification performance concerning the accuracy metric, when the entire

19 dataset and a well-reduced features dataset were involved. In these cases, dimensional reduction does not

20 augment recognition performance but it minimizes the complexity of the feature dataset and consequently

21 reduces the computational cost of the recognition process. This finding can particularly be observed in Lai et

22 al. [50], where the proposed hill-climbing method selected 32 features from an original dataset formed by 512

23 features, making the recognition more cost-effective.

Table 1 Studies that employed feature selection methods as a pre-processing strategy in offline walking recognition

\begin{tabular}{|c|c|c|c|c|c|}
\hline \multirow{2}{*}{ Study } & \multirow{2}{*}{ Method } & \multirow{2}{*}{ Implementation goal } & \multicolumn{2}{|r|}{ Features } & \multirow{2}{*}{ Results } \\
\hline & & & Dataset size & Description & \\
\hline $\begin{array}{l}\text { Eskofier } \\
\text { et al. } \\
{[49]}\end{array}$ & PCA & $\begin{array}{l}\text { Select the spatial and } \\
\text { temporal information } \\
\text { more relevant in the } \\
\text { classification of distinct }\end{array}$ & $\begin{array}{l}84 \text { features } \\
\text { per subject } \\
(48 \text { in total) } \\
\text { from } 10 \text { gait } \\
\text { cycles }\end{array}$ & $\begin{array}{l}84 \text { spatial and temporal } \\
\text { parameters of the segment } \\
\text { motion normalized to 101- } \\
\text { time steps }\end{array}$ & $\begin{array}{l}\text { Maximum accuracy (95.8\%) } \\
\text { was reached when using } 36 \text { to } \\
39 \text { PCs. The worst distinction } \\
\text { between elderly and young }\end{array}$ \\
\hline
\end{tabular}




\begin{tabular}{|c|c|c|c|c|}
\hline & & $\begin{array}{l}\text { gait patterns (elderly and } \\
\text { young healthy subjects) }\end{array}$ & & $\begin{array}{l}\text { gait patterns had an accuracy } \\
\text { of } 58 \% \text { using only } 10 \text { PCs }\end{array}$ \\
\hline $\begin{array}{l}\text { Badesa } \\
\text { et al. } \\
{[38]}\end{array}$ & PCA & $\begin{array}{l}\text { Study the possibility of } 5 \text { features } \\
\text { reducing the number of per subject ( } 7 \\
\text { features in the evaluation in total) and } \\
\text { of distinct machine per gait cycle, } \\
\text { learning approaches along } 5 \text { min } \\
(\mathrm{SVM} \text {, NB, LR, DA, of walking } \\
\mathrm{KNN} \text { ) in the estimation of } \\
\text { physiological states in a } \\
\text { robot-assisted training }\end{array}$ & $\begin{array}{l}\text { Pulse rate, respiration rate, } \\
\text { skin conductance level, skin } \\
\text { conductance response and } \\
\text { skin temperature }\end{array}$ & $\begin{array}{l}\text { The best classification (91.3\% } \\
\text { of accuracy) was achieved } \\
\text { using the } 3 \text { PCs (using feature } \\
\text { extraction) and } 5 \text { PCs (no } \\
\text { feature extraction) in the SVM } \\
\text { classifier, meanwhile the } \\
\text { worst classification ( } 49.52 \% \\
\text { of accuracy) was performed by } \\
\text { NB with } 1^{\text {st }} \text { PC }\end{array}$ \\
\hline
\end{tabular}

\begin{tabular}{|c|c|c|c|}
\hline & & & $\begin{array}{l}8 \text { features per } \\
\text { subject }(113 \\
\text { in total) from }\end{array}$ \\
\hline $\begin{array}{l}\text { Deluzio } \\
\text { et } \quad \text { al. } \\
{[28]}\end{array}$ & PCA & $\begin{array}{l}\text { Select the biomechanical } \\
\text { features that best } \\
\text { characterize the } \\
\text { differences between knee } \\
\text { OA and control groups }\end{array}$ & $\begin{array}{l}5 \text { walking } \\
\text { trials }\end{array}$ \\
\hline
\end{tabular}

Magnitude of flexion angle, range of motion, phase shift of flexion angle, magnitude of flexion moment during stance, amplitude of flexion moment, phase shift of flexion moment, magnitude of adduction moment during stance, magnitude of adduction moment in first half of stance of the knee

\begin{tabular}{|c|c|c|}
\hline $\begin{array}{l}\text { Wu et al. } \\
\text { [36] }\end{array}$ & $\begin{array}{c}\text { PCA } \\
\text { and } \\
\mathrm{kPCA}\end{array}$ & $\begin{array}{l}\text { Evaluate if the kPCA's } \\
\text { use extracts more } \\
\text { significant gait features } \\
\text { than PCA, in the } \\
\text { classification of young- } \\
\text { elderly gait patterns }\end{array}$ \\
\hline
\end{tabular}

36 features Stride length, stride per subject duration, gait velocity, single (48 in total) support duration, stance from 3 duration, swing duration, gait walking trials cadence, and hip, knee and of $10 \mathrm{~m}$ ankle angles and angular range of motion during the stance phases, swing phases and three intervals (heel contact to toe contact, toe contact to heel rise, and heel rise to toe-off

\begin{tabular}{|c|c|c|c|c|}
\hline $\begin{array}{l}\text { Chan et } \\
\text { al. [48] }\end{array}$ & $\begin{array}{c}\text { Hill- } \\
\text { climbing }\end{array}$ & $\begin{array}{l}\text { Assess if the use of hill- } \\
\text { climbing method leads to } \\
\text { a smaller subset of } \\
\text { features to distinguish the } \\
\text { locomotion of younger } \\
\text { and older adults by means } \\
\text { of MLP, SVM, NB, DT } \\
\text { classifiers }\end{array}$ & $\begin{array}{l}14 \text { features } \\
\text { per subject } \\
(25 \text { in total }) \\
\text { from } 93 \\
\text { instances } \\
\text { recorded } \\
\text { along } 4 \text { trials }\end{array}$ & $\begin{array}{l}\text { Cadence, symmetry and step } \\
\text { regularity in the vertical and } \\
\text { anterior- posterior directions, } \\
\text { root mean square, integral of } \\
\text { power spectral density and } \\
\text { stride regularity in the } \\
\text { vertical, medio-lateral, and } \\
\text { anterior- posterior directions }\end{array}$ \\
\hline $\begin{array}{l}\text { Lai et al. } \\
{[50]}\end{array}$ & $\begin{array}{c}\text { Hill- } \\
\text { climbing }\end{array}$ & $\begin{array}{l}\text { Reduce the } \\
\text { computational cost of the } \\
\text { classification with SVM } \\
\text { and extract the most } \\
\text { significant features in the } \\
\text { distinction between } \\
\text { tripping patterns from } \\
\text { healthy patterns of adults }\end{array}$ & $\begin{array}{l}512 \text { values } \\
\text { per subject } \\
(23 \text { in total }) \\
\text { from } 60 \text { gait } \\
\text { cycles } \\
\text { performed } \\
\text { along } 10 \text { min }\end{array}$ & $\begin{array}{l}\text { Minimum toe clearance } \\
\text { values }\end{array}$ \\
\hline $\begin{array}{l}\text { Su et al. } \\
{[44]}\end{array}$ & GA & $\begin{array}{l}\text { Verify if the combination } \\
\text { of GA with ANN } \\
\text { (GANN) is more accurate } \\
\text { than the back- } \\
\text { propagation algorithm in } \\
\text { classification of the gait } \\
\text { patterns of patients with } \\
\text { ankle arthrodesis and } \\
\text { healthy subjects }\end{array}$ & $\begin{array}{l}9 \text { features per } \\
\text { subject }(20 \text { in } \\
\text { total) from } 99 \\
\text { pairs of } \\
\text { footstrikes }\end{array}$ & $\begin{array}{l}\text { Ground-reaction force } \\
\text { parameters normalized to } \\
\text { percentage of gait cycle and } \\
\text { percentage of body weight }\end{array}$ \\
\hline
\end{tabular}

PCA reported that the differences in the gait patterns of patients with knee OA and healthy subjects are characterized by 4 PCs from 8 features. The distinction of the both gait patterns with 4 PCs resulted in an accuracy of $92 \%$

The combination of kPCA and SVM achieved best performance (accuracy of $91 \%$ ) than the combination of PCA with SVM (accuracy of $87 \%$ ), have been selected 17 and 14 PCs from the 36 gait features, respectively. No implementation of PCA and kPCA resulted in an SVM's performance of $85 \%$

The application of hillclimbing allowed increasing the accuracy from $82.9 \%$ to $84.9 \%$ due to dimensional reduction of 14 to 10 gait features

An accuracy of $100 \%$ was achieved when 512, 256, 128 64 and 32 features were combined. The worst accuracy of classification was $52.17 \%$ when are only used 8 features

GANN model classified with accuracy up $98.7 \%$, due to selection of the 5 most relevant features from 9 features, while the back-propagation algorithm (without feature selection method) presented recognition rates of $89.7 \%$ 
According to the reviewed literature $[28,29,38,49]$, we verified that PCA is a widely used technique for

2 dimensional reduction of gait dynamics. However, Wu et al. [36] verified that kPCA is able to extract the PCs

3 that contain more relevant information on nonlinear human movement since it works better than PCA in the

4 presence of random noise in gait data [36]. An inconvenience of both PCA and kPCA is choosing how many components (i.e., gait parameters) will be retained in the analysis. As we can see in Table 1, particularly in studies $[28,38,49]$, the selection of correct number of PCs is fundamental to achieving the best possible recognition. Nevertheless, PCA and kPCA are both filter methods, and consequently, they present less complexity compared to other multivariate statistical approaches.

Comparing the hill-climbing and GA procedures, the included studies highlight that the GA method always converges to a global minimum, whereas hill-climbing can converge to a local optimum $[35,42,44]$.

11 Consequently, to ensure that dimensional reduction increases recognition performance, it is more effective to implement GA rather than hill-climbing. Additionally, GA quantitatively and qualitatively identifies the most

13 relevant gait parameters, without requiring any tuning from the user to indicate the number of features to be 14 extracted. However, GA depends on parameter selection (population size, crossover and mutation probability), 15 and exhibits a higher computational cost than hill-climbing [41].

A particular observation can be formulated by analysing Table 1 and the work proposed in the literature concerning the usual combination of PCA, a long-term studied feature extractor, with the classification model created by SVM $[28,36,38,49]$. In fact, this combination is very popular within the recognition problems and is independent of the application.

In summary, spite the commonly applied of PCA, based on the reviewed information, we verified that kPCA and GA are appropriate methods for dimensional reduction of gait features for classification due to their ability to process nonlinear data (such as biomechanical gait data) and to converge to a global optimum. Additionally, as GA is a wrapper method, it stands out from kPCA, since it additionally considers the classifier performance during feature selection and feature dependencies. However, selection between GA (a wrapper method) and kPCA (a filter method) should consider both the computational cost and need to integrate the classifier during dimensional reduction (e.g., to avoid subjectivity in specifying of the number of features to be removed), as both methodologies provide reliable results. 


\section{Walking Recognition}

A current clinical challenge is to discriminate a healthy gait pattern from a pathological one and to evaluate

the progress of gait disorders during locomotion. For this reason, walking classification methods based on statistical analysis, mathematical transforms, and machine learning approaches have been applied [4]. The statistical analysis approaches have fallen short in meeting the persistent challenges of quantitative and objective analysis, and often, they assume a normal distribution for input data [44,51]. Additionally, mathematical transforms are limited to applications of univariate signals and guideline selection based on wavelets [51].

In contrast, studies $[4,50,52]$ have revealed that machine learning algorithms present a larger ability to both capture patterns and model complex nonlinear relationships in gait data. In addition, these algorithms work appropriately with multidimensional data and easily incorporate newly available data to improve prediction performance [52,53]. The ability to address nonlinear and multidimensional data, such as human gait data, and the capability to properly process newly available data make machine learning approaches suitable methods for human gait pattern recognition. In this sense, this review focuses on machine learning approaches for walking recognition, presenting recent works demonstrating their application in binary and multiclass classifications of gait patterns. The basic principles of machine learning approaches commonly applied in gait classification are described below.

Artificial Neural Networks (ANNs) are a mathematical model inspired by the structure and functional aspects of biological neural systems [42,53]. A standard method of ANNs is a multilayer feedforward neural network that consists of an interconnected set of neurons, where connections between the units only move forward from the input layer to the output layer through hidden layers $[7,51,53]$. The inputs are mapped to nodes through an input layer, and the outputs are controlled by a transfer function within each node, and it is necessary to adjust the weights of links between nodes to reduce the error function $[7,51,53]$.

Support Vector Machine (SVM) is a supervised leaning classifier that employs kernel methods (e.g., linear, polynomial, and Gaussian RBF) to map nonlinear data (e.g., human gait data, mainly pathological data) to a higher dimensional feature space. Classification is performed in this feature space by finding an optimal separating hyperplane between the analysed classes [26,46,53]. For this optimization problem, parameter $C$ (trade-off between maximum width of margin and minimum classification error) is computed [26,46,54]. Although there are no analytical studies on optimal kernel function, Gaussian RBF is widely suggested as the 
most convenient option for inter-individual gait classification [55] due to its smoothing behaviour in treating

2 the datasets of interest. The multiclass classification is usually conducted by "one-against-one" and "oneagainst-all” approaches [56].

Naïve Bayes (NB) assumes that all features are independent of each other according to Bayes' theorem $[38,48]$. First, the NB classifier creates a probabilistic model that estimates the probability that an input sample belongs to a certain class. For biomechanical gait data, the probabilistic model is commonly implemented by means of a normal distribution $[38,48]$. Then, a decision rule is applied to attribute the data to the most likely class $[38,48]$.

Logistic Regression (LR) is a discriminative model for classification that applies maximum likelihood estimation after transforming the output into a logic variable [30,57]. In this way, LR estimates the probability of input features belonging or not belonging to a certain class [30,57].

Discriminant Analysis (DA) aims to find a linear (linear discriminant analysis - LDA) or quadratic (quadratic discriminant analysis - QDA) combination of input features by separating input data into two or more classes, according to a least square sense $[38,57,58]$. Each input feature has its own assigned weight, which indicates the importance of this feature in discriminating between classes [38].

Clustering Analysis (CA) classifies a data set into homogeneous groups or "clusters". There are hierarchical and non-hierarchical clustering methods that strive to minimize the variability within clusters and maximize the variability between clusters [59]. In the scope of gait recognition, fuzzy logic clustering is commonly used since it offers an insight into nonlinear relationships among gait variables [60]. It also allows that each input data simultaneously has partial memberships in multiple clusters, and thus a sharp boundary does not exist between clusters $[4,60]$. Furthermore, K-Nearest Neighbours $(\mathrm{KNN})$ is a non-hierarchical clustering method that defines that the properties of input data based on likely similarity to their neighbours $[7,38]$. The neighbourhood is defined to include $k$ points, and a distance metric (e.g., Euclidean distance) is used to identify the nearest neighbours of a query point [38]. Thus, $k$ (where $k \geq 1$ ) nearest training samples are used to classify the new sample with the most common class of $k$ samples.

\subsection{Assessment of Recognition Performance}

To evaluate the performance of machine learning approaches in gait pattern recognition, three dimensions, namely, accuracy, sensitivity and specificity are commonly used, as shown in Fig. 1. These metrics are obtained 
1 based on a confusion matrix [53]. Accuracy, as expressed in equation (1), is the most common and simplest

2 measure to evaluate a classifier, and is defined as the degree of correct predictions of a model by using true

3 positive (TP), false positive (FP), true negative (TN) and false negative (FN) values [33,35].

$$
\text { Accuracy }(\%)=\frac{\mathrm{TN}+\mathrm{TP}}{\mathrm{TP}+\mathrm{TN}+\mathrm{FP}+\mathrm{FN}} \times 100 \%
$$

Sensitivity, as presented in equation (2), measures the proportion of actual positives that are correctly

5 identified as such.

$$
\text { Sensitivity }(\%)=\frac{\mathrm{TP}}{\mathrm{TP}+\mathrm{FN}} \times 100 \%
$$

Specificity, as showed in equation (3), measures the proportion of negatives that are correctly identified [35].

7 It is possible to determine the negative likelihood ratio (NLR), a ratio between false and true negatives, through 8 a confusion matrix [30].

$$
\text { Specificity }(\%)=\frac{\mathrm{TN}}{\mathrm{TN}+\mathrm{FP}} \times 100 \%
$$

9 Another criterion recommended to assess the classification performance, independently of the a priori

10 distribution of classes, is AUC [46,48,61]. It presents higher convergence than accuracy and represents the 11 average sensitivity across all possible specificities [30]. AUC is determined through integration by the trapezoid 12 method base on the Receiver Operating Characteristic, a graphic that visualizes the trade-off between the TP 13 rate and FP rate $[46,50,53,62]$.

\section{$14 \quad 4.2$ Search Results and Discussion}

15 Table 2 lists the most relevant studies since 2000 that employed gait dynamics in machine learning approaches (instead of image-specific features) to discriminate pathological/healthy and young/elderly gait

17 patterns and deficits in the postural balance offline. For each reviewed work, we provide a summary of the study 18 goal, study volunteers, gait dynamics used as features for classification, implemented methods for feature 19 selection, cross-validation and feature normalization, applied machine learning algorithms, and findings of gait 20 pattern recognition. Instances of gait dynamics are ground reaction force (GRF), an indicator of kinetic 21 interaction with the ground, and the minimum foot clearance (MFC), an event that occurs during the mid-swing phase of the gait cycle. 
Table 2 Studies that applied machine learning approaches for offline gait pattern recognition

\begin{tabular}{|c|c|c|c|c|c|c|c|c|}
\hline Study & Study's goal & Participants & Gait dynamics & $\begin{array}{c}\text { Feature } \\
\text { selection }\end{array}$ & $\begin{array}{c}\text { Cross- } \\
\text { Validation }\end{array}$ & Normalization & Classifiers & Results \\
\hline $\begin{array}{l}\text { Alaqtash } e t \\
\quad \text { al. [7] }\end{array}$ & $\begin{array}{c}\text { Automatic } \\
\text { classification of } \\
\text { pathological gait } \\
\text { patterns (CP and ME) } \\
\text { from healthy walking }\end{array}$ & $\begin{array}{c}12 \text { healthy subjects (age } \\
27.1 \pm 5.9 \text { years), } 4 \mathrm{CP} \\
\text { (age } 29.5 \pm 17.5 \text { years) } \\
\text { and } 4 \text { patients ME (age } \\
50.3 \pm 11.5 \text { years) }\end{array}$ & $\begin{array}{c}19 \text { features based on } \\
\text { amplitude and temporal } \\
\text { parameters of GRFs }\end{array}$ & $\begin{array}{c}\text { M-shaped } \\
\text { value and } \\
\text { test } \\
\text { ANOVA }\end{array}$ & LOO & $\begin{array}{c}\text { Stride-time } \\
\text { normalization }\end{array}$ & KNN and ANN & $\begin{array}{l}\text { KNN was more accurate than } \\
\text { ANN (accuracy of } 85 \% \text { against } \\
80 \% \text { ) in the classification of } 3 \\
\text { gait patterns through GRFs data }\end{array}$ \\
\hline $\begin{array}{l}\text { Mohamma } \\
\text { d [45] }\end{array}$ & $\begin{array}{c}\text { Automatic diagnosis } \\
\text { of neuro-degenerative } \\
\text { diseases (PD, } \\
\text { Huntington's disease } \\
\text { and ME) }\end{array}$ & $\begin{array}{c}15 \text { subjects with PD } \\
\text { (age } 66.8 \pm 2.8 \text { years), } \\
20 \text { patients with } \\
\text { Huntington's disease } \\
\text { (age } 46.65 \pm 2.81 \text { years), } \\
13 \text { participants with } \\
\text { ME (age } 55.61 \pm 3.56 \\
\text { years) and } 16 \text { healthy } \\
\text { subjects (age } \\
39.31 \pm 4.62 \text { years) }\end{array}$ & $\begin{array}{c}\text { Temporal parameters: } \\
\text { stride, cadence, double } \\
\text { support, swing and stance } \\
\text { interval ( } 28 \text { samples per } \\
\text { subject) }\end{array}$ & GA & NA & NA & SVM & $\begin{array}{c}\text { SVM distinguished the } 3 \text { neuro- } \\
\text { degenerative diseases of healthy } \\
\text { gait patterns with accuracy of } \\
90.65 \%\end{array}$ \\
\hline $\begin{array}{c}\text { Laroche et } \\
\text { al. }[62]\end{array}$ & $\begin{array}{c}\text { Distinguish the gait } \\
\text { patterns of an OA } \\
\text { patient from a control } \\
\text { subject }\end{array}$ & $\begin{array}{l}20 \text { healthy subjects (age } \\
63.82 \pm 6.55 \text { years) and } \\
20 \text { knee OA patients } \\
\text { (age } 62.23 \pm 6.24 \text { years) }\end{array}$ & $\begin{array}{l}12 \text { features extracted from } \\
\text { 3D kinematics ( } 1 \text { sample } \\
\text { per each subject's stride in } \\
\text { a total of } 10 \text { gait cycles })\end{array}$ & NA & 5-fold CV & $\begin{array}{l}\text { Body weight- } \\
\text { normalization }\end{array}$ & SVM & $\begin{array}{c}\text { SVM distinguished the gait } \\
\text { patterns of OA and healthy } \\
\text { participants with an accuracy of } \\
88 \%\end{array}$ \\
\hline $\begin{array}{l}\text { Pogorelc et } \\
\quad \text { al. [5] }\end{array}$ & $\begin{array}{c}\text { Implement an early } \\
\text { automatic recognition } \\
\text { tool of distinct } \\
\text { abnormal gait } \\
\text { patterns }\end{array}$ & $\begin{array}{l}5 \text { healthy and } 9 \\
\text { pathological elderly } \\
\text { subjects (over } 65 \text { years): } \\
\text { (hemiplegia, PD, pain in } \\
\text { the back, pain in the leg) }\end{array}$ & $\begin{array}{l}13 \text { features (angles, } \\
\text { spatiotemporal parameters) } \\
\text { from shoulders, elbows, } \\
\text { hips, knees and ankles (141 } \\
\text { samples in total) }\end{array}$ & NA & 10-fold CV & NA & $\begin{array}{c}\text { Five-class } \\
\text { classification } \\
\text { with SVM, DT, } \\
\text { KNN, NB and } \\
\text { ANN }\end{array}$ & $\begin{array}{c}\text { Accuracy of } 97.9 \%, 90.1 \%, \\
100 \%, 97.2 \%, 100 \% \text { for SVM, } \\
\text { DT, KNN, NB, and ANN, } \\
\text { respectively }\end{array}$ \\
\hline $\begin{array}{c}\text { Kaczmarcz } \\
\text { yk et al. } \\
\text { [59] }\end{array}$ & $\begin{array}{l}\text { Gait pattern } \\
\text { classification of post- } \\
\text { stroke patients in } 3 \\
\text { different foot } \\
\text { positions: forefoot, } \\
\text { flatfoot and heel }\end{array}$ & $\begin{array}{l}74 \text { post-stroke patients } \\
\text { (age } 55.6 \pm 9.4 \text { years) }\end{array}$ & $\begin{array}{l}11 \text { kinematic variables of } \\
\text { knee joint, sagittal and } \\
\text { frontal hip joint (1 per } \\
\text { subject along } 10 \mathrm{~m})\end{array}$ & NA & NA & $\begin{array}{c}\text { Stride-time } \\
\text { normalization }\end{array}$ & $\begin{array}{l}\text { ANN (51 input } \\
\text { units, one } \\
\text { hidden layer of } \\
27 \text { units and } \\
\text { one three-level } \\
\text { output unit) }\end{array}$ & $\begin{array}{l}\text { ANN correctly classified the } \\
\text { post-stroke patterns (accuracy } \\
\text { of } 100 \% \text { ) when the heel is the } \\
\text { first contact }\end{array}$ \\
\hline $\begin{array}{l}\text { Begg et al. } \\
\text { [46] }\end{array}$ & $\begin{array}{l}\text { Classification of gait } \\
\text { patterns of young and } \\
\text { elderly subjects }\end{array}$ & $\begin{array}{l}30 \text { young healthy (age } \\
28.6 \pm 6.4 \text { years) and } 28 \\
\text { elderly participants (age } \\
69.2 \pm 5.1 \text { years) }\end{array}$ & $\begin{array}{l}\text { Minimum, maximum, } \\
\text { median, } 1^{\text {st }} \text { and } 3^{\text {rd }} \text { quartile } \\
\text { values of MFC }(1 \text { sample of } \\
\text { each swing phase per } \\
\text { subject that walked } 20 \mathrm{~min})\end{array}$ & $\begin{array}{l}\text { Hill- } \\
\text { climbing }\end{array}$ & 3-fold CV & $z$-score & $\begin{array}{l}\text { ANN (three- } \\
\text { layer) and SVM } \\
\text { (linear, } \\
\text { polynomial and } \\
\text { RBF kernels) }\end{array}$ & $\begin{array}{l}\text { The best distinction of both gait } \\
\text { patterns was achieved with SVM } \\
\text { using linear kernel (accuracy of } \\
83.3 \% \text { ), while the ANN showed } \\
\text { the worst accuracy }(75 \%)\end{array}$ \\
\hline
\end{tabular}




\begin{tabular}{|c|c|c|c|c|c|c|c|c|}
\hline $\begin{array}{l}\text { Begg et al. } \\
{[26]}\end{array}$ & $\begin{array}{l}\text { Classification of gait } \\
\text { patterns of young and } \\
\text { elderly subjects }\end{array}$ & $\begin{array}{l}12 \text { young healthy (age } \\
28.1 \pm 5.6 \text { years) and } 12 \\
\text { elderly subjects (age } \\
68.8 \pm 4.6 \text { years) }\end{array}$ & $\begin{array}{l}24 \text { spatiotemporal, } \\
\text { kinematic and kinetic } \\
\text { parameters (1 sample per } \\
\text { stride, per subject recorded } \\
\text { along } 3 \text { trials of } 15 \mathrm{~m})\end{array}$ & $\begin{array}{l}\text { Hill- } \\
\text { climbing } \\
\text { (forward } \\
\text { selection } \\
\text { algorithm) }\end{array}$ & 6-fold CV & $z$-score & $\begin{array}{l}\text { SVM (linear, } \\
\text { polynomial and } \\
\text { RBF kernels) }\end{array}$ & $\begin{array}{l}\text { SVM with linear, polynomial } \\
\text { and RBF kernel achieved the } \\
\text { same accuracy }(91.7 \%)\end{array}$ \\
\hline $\begin{array}{l}\text { Chan et al. } \\
\text { [48] }\end{array}$ & $\begin{array}{lr}\text { Gait } & \text { patterns } \\
\text { classification } & \text { of } \\
\text { younger and older } \\
\text { individuals }\end{array}$ & $\begin{array}{l}13 \text { healthy younger (age } \\
27.7 \pm 7.3 \text { years) and } 12 \\
\text { healthy older adults } \\
\text { (age } 70.0 \pm 3.7 \text { years) }\end{array}$ & $\begin{array}{l}14 \text { features: root mean } \\
\text { square, integral of power } \\
\text { spectral density, cadence, } \\
\text { stride and step in the } \\
\text { vertical, medio-lateral and } \\
\text { anterior- posterior } \\
\text { directions (93 samples: } 1 \\
\text { per stride and per subject } \\
\text { recorded from } 4 \text { gait trials) }\end{array}$ & $\begin{array}{l}\text { Pearson } \\
\text { Correlation- } \\
\text { based } \\
\text { method }\end{array}$ & 10-fold CV & NA & $\begin{array}{l}\text { MLP, KSart, } \\
\text { SVM with } \\
\text { polynomial } \\
\text { kernel, NB and } \\
\text { DT }\end{array}$ & $\begin{array}{l}\text { MLP achieved the best accuracy } \\
(80.6 \%) \text { to discriminate young } \\
\text { and elderly gait patterns }\end{array}$ \\
\hline $\begin{array}{l}\text { Eskofier et } \\
\text { al. [49] }\end{array}$ & $\begin{array}{lr}\text { Gait } & \text { patterns } \\
\text { classification } & \text { of } \\
\text { younger and elderly } \\
\text { subjects }\end{array}$ & $\begin{array}{l}24 \text { young healthy (age } \\
25.3 \pm 2.4 \text { years) and } 24 \\
\text { elderly subjects (age } \\
59.9 \pm 4.5 \text { years) }\end{array}$ & $\begin{array}{l}84 \text { spatial and temporal } \\
\text { parameters ( } 1 \text { per subject } \\
\text { along } 10 \text { gait cycles) }\end{array}$ & PCA & $\mathrm{LOO}$ & $\begin{array}{l}\text { Stride-time } \\
\text { normalization }\end{array}$ & $\begin{array}{l}\text { SVM with a } \\
\text { linear kernel }\end{array}$ & $\begin{array}{l}\text { SVM distinguished the two } \\
\text { patterns with an accuracy of } \\
95.8 \%\end{array}$ \\
\hline $\begin{array}{l}\text { Khandoker } \\
\text { et al. [47] }\end{array}$ & $\begin{array}{l}\text { Automatic } \\
\text { recognition of gait } \\
\text { patterns related to } \\
\text { balance impairments }\end{array}$ & $\begin{array}{l}13 \text { healthy adults (age } \\
67.5 \pm 2.1 \text { years) and } 10 \\
\text { subjects with history of } \\
\text { falls (age } 68.2 \pm 3.1 \\
\text { years) }\end{array}$ & $\begin{array}{l}\text { MFC data from the first } 512 \\
\text { continuous gait cycles of } \\
\text { each subject }\end{array}$ & $\begin{array}{l}\text { Hill- } \\
\text { climbing }\end{array}$ & LOO & NA & $\begin{array}{l}\text { SVM with } \\
\text { linear, } \\
\text { polynomial and } \\
\text { RBF kernels }\end{array}$ & $\begin{array}{l}\text { Polynomial kernel performed } \\
\text { better (accuracy of } 100 \% \text { ) than } \\
\text { linear (accuracy of } 86.95 \% \text { ) and } \\
\text { RBF (accuracy of } 86.95 \% \text { ) } \\
\text { kernels }\end{array}$ \\
\hline $\begin{array}{l}\text { Lai et al. } \\
{[54]}\end{array}$ & $\begin{array}{l}\text { Propose a gait } \\
\text { recognition system to } \\
\text { detect fall patterns }\end{array}$ & $\begin{array}{l}13 \text { healthy subjects (age } \\
71.0 \pm 2.1 \text { years) and } 10 \\
\text { individuals that had } \\
\text { suffered tripping fall } \\
\text { (age } 72.2 \pm 2.1 \text { years) }\end{array}$ & $\begin{array}{l}\text { Autoregressive coefficients } \\
\text { of } 512 \mathrm{MFC} \text { values from } 60 \\
\text { gait cycles performed along } \\
10 \mathrm{~min}\end{array}$ & $\begin{array}{l}\text { Autoregress } \\
\text { ive model }\end{array}$ & LOO & NA & $\begin{array}{l}\text { SVM with } \\
\text { linear, } \\
\text { polynomial and } \\
\text { RBF kernel } \\
\text { functions }\end{array}$ & $\begin{array}{l}\text { The best was achieved with } \\
\text { linear and RBF kernel (accuracy } \\
\text { of } 95.6 \% \text { ), using only } 32 \text { MFC } \\
\text { samples }\end{array}$ \\
\hline $\begin{array}{l}\text { Mao et al. } \\
\text { [63] }\end{array}$ & $\begin{array}{l}\text { Classification of } 3 \\
\text { walking patterns: } \\
\text { walk stably, } \\
\text { intermediary risks of } \\
\text { tumble, and high risk } \\
\text { of tumble }\end{array}$ & 36 subjects & $\begin{array}{l}\text { Maximum, mean and } \\
\text { standard deviation values of } \\
4 \text { local motions (motion of } \\
\text { head, center of gravity, } \\
\text { motion of pelvis, motion of } \\
\text { toe) from the first } 6 \text { steps }\end{array}$ & NA & NA & $\begin{array}{l}\text { Body height } \\
\text { normalization }\end{array}$ & $\begin{array}{l}\text { Multiclass } \\
\text { classification } \\
\text { with SVM }\end{array}$ & $\begin{array}{l}\text { The three classes were } \\
\text { recognized with accuracy of } \\
84.5 \%\end{array}$ \\
\hline $\begin{array}{l}\text { Zhang et al. } \\
\text { [33] }\end{array}$ & $\begin{array}{l}\text { Recognition of gait } \\
\text { patterns during lower } \\
\text { extremity muscular } \\
\text { fatigue and no-fatigue }\end{array}$ & $\begin{array}{l}17 \text { healthy subjects (age } \\
29 \pm 11 \text { years) }\end{array}$ & $\begin{array}{l}\text { Step width, step length, } \\
\text { stride duration, heel contact } \\
\text { velocity, and stance time (1 } \\
\text { sample per subject, per } \\
\text { stride along } 5 \text { trials) }\end{array}$ & $\begin{array}{l}\text { Kernel } \\
\text { function } \\
\text { selection } \\
\text { method }\end{array}$ & 5-fold CV & $\begin{array}{l}\text { Stride-time } \\
\text { normalization }\end{array}$ & $\begin{array}{l}\text { SVM with } \\
\text { linear, } \\
\text { polynomial and } \\
\text { RBF kernels }\end{array}$ & $\begin{array}{l}\text { SVM with linear and RBF } \\
\text { kernels recognized the fatigued } \\
\text { and no-fatigued gait with an } \\
\text { accuracy of } 96 \%\end{array}$ \\
\hline
\end{tabular}


Considering the inclusion criteria proposed for this review, we included thirteen studies in this analysis. Five studies (38.46\% of studies) focused on the automatic diagnosis of pathologic gait patterns by including a control group formed by healthy subjects with similar demographic features (age and gender) $[5,7,45,59,62]$ Four works (30.76\% of studies) recognized the gait patterns of younger and older individuals $[26,46,48,49]$. Additionally, another study [47] carried out an automatic recognition of gait patterns related to balance impairments, whereas one study [33] investigated the differences between lower extremity muscular fatigue and non-fatigue. The remaining two studies $[54,63]$ proposed a system to detect tripping fall patterns.

By analysing Table 2, we verified that all included studies investigated the performance of SVM for classification purposes, and seven of these studies (53.85\%) only implemented this machine learning approach. Five of these studies $(38.46 \%)$ compare the effects introduced by different SVM kernels $[26,33,46,49,54]$.

11 Additional machine learning algorithms were explored and compared to SVM namely, ANN (38.46\% of studies) [5,7,46,48,59], KNN (15.39\% of studies) [5,7], NB (15.39\% of studies) [5,48], and DT (15.39\% of studies) [5,48].

The majority of the reviewed studies (9 studies, 69.23\%) applied feature selection methods [7,26,33,4549,54], particularly hill-climbing [26,46,47], PCA [49], and GA [45], among other statistical approaches. Additionally, ten studies (76.92\%) improved the generalized ability of machine learning approaches by integrating CV methods namely, integrating a conventional CV scheme with different $k$-folds (3-fold [46], 5fold [33,62], 6-fold [26], and 10-fold [48]), and the LOO method [7,47,49,54]. Normalization techniques were also performed in eight of the thirteen studies $(61.54 \%)$ through the $z$-score method $[26,46]$ and normalizations as a function of stride duration $[7,33,49,59]$ and participant body weight $[62,63]$.

Diverse pattern recognition methods can be investigated in the scope of human gait, as described in Table 2 .

22 From the included studies, we listed some benefits and limitations of the most commonly applied machine 23 learning approaches for gait analysis.

24 ANN is considered an algorithm with learning capability, adaptability, and ability to address nonlinear data.

25 Nevertheless, this classifier and its feedforward algorithms (MLP, PNN, and TDNN), depend on a large number 26 of parameters for a correct generalization, can get trapped in a local minimum, and can conduct an over-fitting 27 of the training data, harming the generalization of recognition [26,46,50,51]. 
On the other hand, SVM converges to a global optimum and avoids over-fitting in the training process

2 [31,36]. SVM also has the ability to minimize both structural and empirical risks leading to better generalization of a new classification even, with a limited training data set, and producing stable and reproducible results

$4 \quad[26,46,47]$.

5 A drawback of both SVM and ANN classifiers lies in their dependence on delicate and computationally 6 expensive hyperparameter tuning of learning parameters (e.g., weights and biases and network size for NN and regularization parameter for SVM) [4,7,64].

CA is very sensitive to variables that are highly correlated, making it necessary to determine and remove these variables [65]. This approach also requires that the number of a priori rules and the number of clusters are set $a$ priori by the user, implying a subjective judgment [60,64]. However, CA based on fuzzy logic exhibits the benefits of offering insight into nonlinear relationships among gait variables, providing a quantitative comparison, less complexity and fast processing time [4].

Although NB and LR are two probabilistic models, LR does not assume linearity in the relationship between input and output variables and does not assume homoscedasticity; therefore, it does not simplify the computational cost [57].

An advantage of DT and KNN is that the problem of context recognition is divided into smaller subproblems, which are approached one by one intuitively [66]. Nevertheless, KNN requires the definition of a distance metric, whereas a split criterion must be set in DT.

Due to the deviant behavior of these machine learning approaches, benchmarking can be performed to select the optimal machine learning method for a specific application. For instance, Harper [57] compared DA, DT, ANN and LR methods with distinct datasets and showed that there is not necessarily a single best classification tool; but instead, the best performance of the algorithm will depend on the analyzed features [57]. Other authors have concluded that combining the output of different classifiers can improve classification performance [7].

24 Additional studies have highlighted that classifier performance depends on many factors, such as the type of input features, dataset size, relevance of involved features, and number of subjects $[26,38,50]$. us to observe that in general, SVM is the most accurate classifier for treating gait data, mainly when a Gaussian 
concluded that SVM with linear and RBF kernels performs better than ANN (accuracy of $83.3 \%$ versus 75\%); and, Badesa et al. [38], who noted that SVM with RBF kernel is more appropriate than LR, LDA, QDA, NB or KNN methods. Additionally, Zheng et al. [52] investigated the performance of three classifiers (SVM, Random Forest, and KStar) in gait pattern recognition of three neurodegenerative diseases and control subjects. Their results showed that SVM is the most appropriate method to recognize these four classes (control group and three pathologic groups) [52]. Moreover, other studies mentioned that SVM creates a more efficient algorithm than LDA [36,62] and ANNs [26]. Lastly, Novak et al. [67] reported that SVM is the most used classification method with a median accuracy rate of $78.76 \%$, whereas the less used classification methods are fuzzy logic and NB with median accuracy rates of $76.05 \%$ and $74.70 \%$, respectively [67].

These findings noted that SVM is an accurate classifier in a range of either binary or multiclass recognition tasks concerning healthy and pathological gait and situations of balance instability. The high recognition rates result from SVM's ability to define more complex decision boundaries by applying optimization problems instead of probabilistic ones. Due to this property, SVM classifiers are robust to data bias and data variance, which are commonly observed in human gait data given their inter-subject and inter-step variability, mainly when pathologic gait patterns are considered. Simultaneously, SVM can properly work with the inherent nonlinear character of human gait data and can manage high-dimensional and multidisciplinary data (e.g., spatiotemporal, kinetic, and kinematic parameters) recorded from distinct sensory technologies (either external or wearable sensors). Thus, SVM presents a strong ability to model versatile, complex and nonlinear datasets, such as ones associated with pathological conditions. However, it is worth mentioning that this comparative analysis does not take into consideration the computational cost of the analyzed machine learning approaches. In general, LR has the fastest computational-times, although compared to DT and DA the time difference is likely insignificant in practice. ANN requires significantly more time to train and validate models [57]. Lastly, regarding complexity and the demonstration of reliable performance, SVM is an appropriate tool for offline walking recognition.

\section{Approaches to Improving Walking Recognition}

In this section, we describe feasible approaches to improving human walking recognition namely, feature normalization and cross-validation methodologies (see scheme in Fig. 1). 
$\mathrm{CV}$ methods are commonly involved in machine learning approaches as a model assessment technique to evaluate their inter-subject generalization for classifying new instances, mainly when datasets are limited $[26,35,36,61]$ and when they involve pathological information (which exhibits widely variability), as highlighted in Table 2. Moreover, CV methods have the potential to minimize over-fitting of machine learning approaches since the training set is further partitioned into two disjoint subsets: the training subset used to train the learning model; and, the validation subset used to validate the model. In turn, the validation dataset can be used to determine the performance of various candidate models; and thereby select the most general and accurate model [68].

The conventional CV method begins with partitioning a sample into two complementary subsets, the training set and the test set, based on $k$-fold. Thus, the original sample is randomly partitioned into $k$ roughly equal size sub-samples, a single sub-sample is used as the validation data for testing the classifier, and the remaining $k$ - 1 sub-samples are used as training data. Consequently, the CV process is repeated $k$ times until every gait trial of

13 the dataset is included in the testing dataset. Lastly, the average of the $k$ results is calculated to obtain a single 14 performance estimation $[4,7,35,61,69]$. The advantage of this method is that it matters less how the data gets divided. In the literature, there is no a stipulated number for $k$-fold, although many studies have implemented a 10-fold [5,48,70] or 5-fold CV scheme [33,62].

However, recent studies preferred LOO [7,47,49,54], a robust CV procedure, since it does not randomly partition the data. Instead, data in each fold belong to a particular participant $[7,38,50,53,66]$, i.e., LOO partitions data using the $k$-fold approach where $k$ is equal to the total number of observations in the data. In addition, López et al. [61] considered that CV is not appropriate in situations of unbalanced and covariate data since it may introduce a different data distribution between the training and test partitions by equally partitioning the number of samples of each class on each partition [61]. According to López et al. [61], the distribution optimally balanced stratified cross-validation (DOB-SCV) is a proper methodology that avoids both unbalanced and covariate data issues [61]. DOB-SCV picks a random unassigned example and then finds its $k-1$ nearest unassigned neighbors of the same class. Posteriorly, $k$ closest neighbors are placed in different folds (with $k$ being the number of total partitions) to maintain the data distribution between the training and validation partitions [61]. The process is repeated until there are no more instances [61]. Fig. 2 illustrates a graphical representation of these different $\mathrm{CV}$ methods to elucidate the principles of each method. 

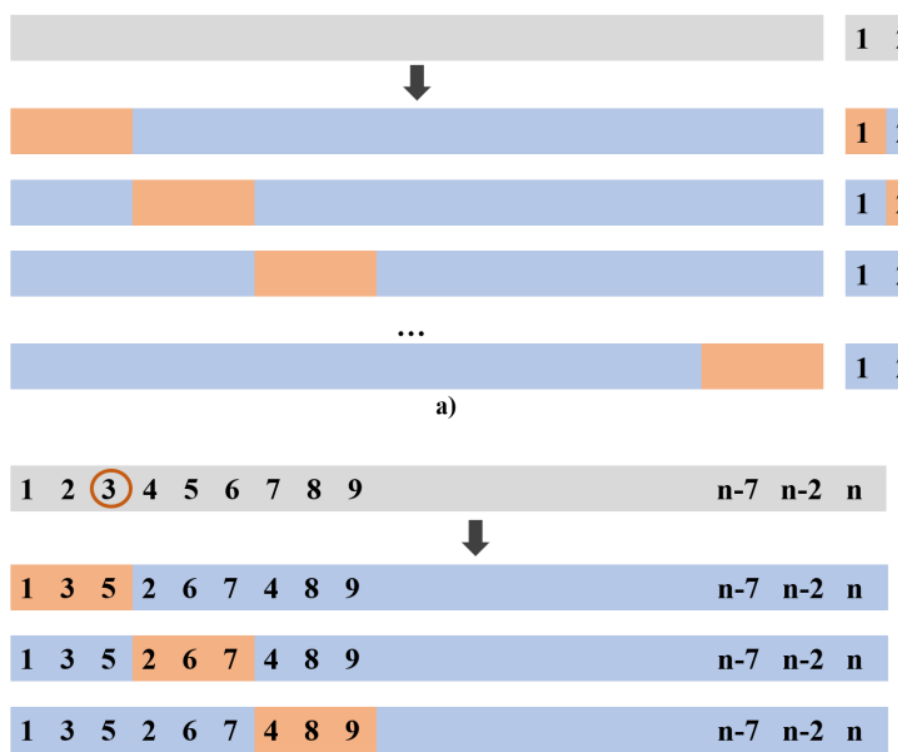

$\begin{array}{llllllllllllll}1 & 3 & 5 & 2 & 6 & 7 & 4 & 8 & 9 & & n-7 & n-2 & n\end{array}$

Original Training Dataset

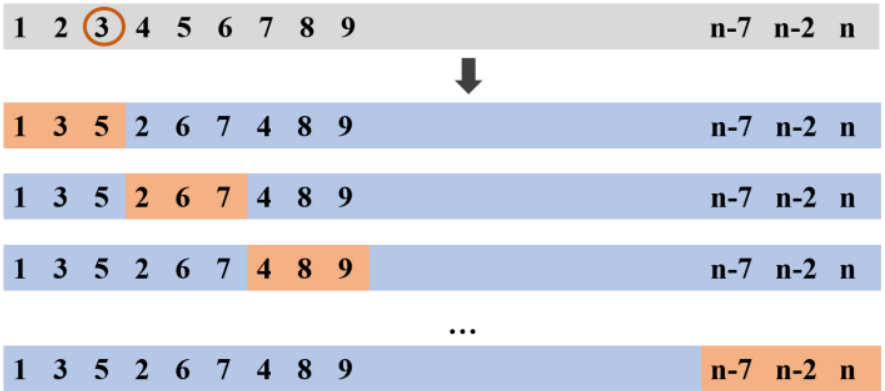

$\ldots$

b)

c)

Fig. 2 Graphical representation of CV methods: a) conventional $k$-fold CV method, where the original training dataset was partitioned in $k$ partitions; b) LOO CV method, which uses each sample (identified by 1, 2, 3, .. n) as a validation fold; c) DOB-SCV method, where for instance, sample 3 (randomly selected) and its neighbors 2 and 4 where assigned to different folds.

Another approach commonly used to make the classifiers more robust and improve their accuracy is the prior standardization of features [26,36,71], as outlined in Table 2. For this purpose, the $z$-score is often implemented on the original feature as set by equation (4), where $x$ is the feature, $\mu$ is the mean and $\sigma$ is the standard deviation $[26,36,46]$. Thus, each feature has a mean of zero and a variance of one $[3,33]$.

$$
\frac{x-\mu}{\sigma}
$$

Time normalization is also a common standardization method that expresses each feature as a function of the stride (gait cycle) in percentages rather than in time $[4,7,33,49,59]$. A similar strategy has also been applied to kinematic features through participants body weight instead of the stride duration $[62,63]$.

13 In addition, there are specific methodologies for each machine learning approach. To avoid ANN over-

14 fitting, techniques other than CV methods, such as regularization, pruning or Bayesian model comparison, can

15 be used to indicate the tipping point when further training no longer results in a better performance [53]. Additionally, Begg et al. [46] proposed a scaled conjugate gradient algorithm to adjust the weights of the ANNs since it allows training of the relationship between gait features and the respective gait class [46]. Su et al. [44] demonstrated that the combination of a GA algorithm with ANN is more accurate than the implementation of 
1 ANN based on a back-projection algorithm. The performance of SVM is extremely dependent on tuning of the

2 regularization parameter (parameters $C$ and $\sigma$ ), and therefore, a grid-search is often implemented to find the best

3 values of $C$ and $\sigma$, minimizing the misclassification error [46,47]. Hsu et al. [72] recommend that the grid-search

4 is combined with a CV method to ensure that the values are most appropriate for the input dataset [72].

5 The described approaches represent some strategies able to improve the classifier performance during gait

6 pattern recognition, aside from the implementation of feature selection methods. Indeed, we verify that the

7 implementation of these approaches, or other ones with the same purpose, contributes significantly to the

8 reliability of the developed recognition tool.

\section{Conclusions}

10 This literature review covers the state-of-the-art on machine learning approaches, and their respective pre-

11 processing methodologies, for human pattern gait recognition using gait dynamics. The reviewed methods may

12 vary based on supervised and unsupervised learning; linearity and nonlinearity models; the possibility of leading

13 to over-fitting or not; division of classification in training and test phases or not; and on the necessity of defining

14 split criteria or not.

15 Human gait pattern recognition is a powerful automatic tool that may provide an objective analysis of

16 abnormal gait patterns, by manipulating nonlinear and massive multidimensional datasets. Recent studies have

17 evidenced that wearable sensory systems provide these datasets given their potential for long-term and free-

18 setting applications, and a time- and cost-effectiveness.

19 From this literature analysis, we verify that proper and reliable gait pattern recognition should involve several

20 phases. The first phase is feature extraction to characterize the gait pattern (e.g., healthy/pathological, or

21 old/young). Second, methods of feature normalization may be applied to achieve a more robust classification.

22 Then, feature selection methods are implemented to select the most significant features to distinguish the classes

23 based on dependence of classifier performance on the number and type of features. kPCA and GA are promising

24 methods for dimensional reduction of gait parameters due to their ability to work with nonlinear data and

25 converge on a global optimum. The next stage before the classification algorithm is to form the training and

26 testing datasets through CV procedures, mainly LOO. CV methods also prevent over-fitting and generalize the

27 classifier performance. The implementation of these three methodologies provides the answer to the second

28 search question raised in this review since these are reliable tools that improve the performance of walking 
1 recognition. Out of the three existing classification methods, machine learning approaches are the most

2 successful ones when applied in gait pattern recognition due to their ability to work well with multidimensional

3 nonlinear features. Nevertheless, SVM stood out as an accurate tool that converges to a global minimum, does

4 not lead to over-fitting, and minimizes both structural and empirical risk, leading to better generalization for

5 new data classification. The main limitation of SVM is its dependence on a proper choice of input parameters,

6 which can be solved by combining a grid-search with the CV method. In response to the first search question

7 proposed in this review, we have concluded that SVM has the potential to become a powerful tool for human

8 walking recognition in clinical applications.

9 In summary, an automatic recognition of gait disorders through machine learning algorithms is likely to offer 10 an objective and prompt assessment of the subject's clinical status and hence, provides a potentially realistic 11 diagnosis. However, the classification of data is not necessarily equivalent to diagnosis, as there should be 12 sufficient clinical evidence supporting such an argument in specific cases/conditions. This fact agrees with a 13 major drawback of the described techniques which is that they do not consider the subject's clinical history.

14 Future directions involve the successful application of machine learning approaches in real-time monitoring 15 of human gait during daily living activities. This scenario will provide a more reliable, prompt, and cost16 effective diagnosis of locomotion. Moreover, real-time recognition and assessment of gait patterns can drive 17 powered assistive devices and promptly plan task-oriented therapy in pathological conditions.

\section{Funding}

19 This work was supported by the FCT - Fundação para a Ciência e Tecnologia - with the reference scholarship 20 SFRH/BD/108309/2015, and the reference project UID/EEA/04436/2013, by FEDER funds through the 21 COMPETE 2020 - Programa Operacional Competitividade e Internacionalização (POCI) - with the reference project POCI-01-0145-FEDER-006941. Also, this work was partially supported by grant RYC-2014-16613 by

23 Spanish Ministry of Economy and Competitiveness.

\section{Declaration Statement}

25 The authors declare that they have no competing or conflict of interests.

26 Ethical approval: Not required. 


\section{References}

2 [1] Lakany H. Extracting a diagnostic gait signature. Pattern Recognit 2008;41:1627-37. doi:10.1016/j.patcog.2007.11.004.

4 [2] Rueterbories J, Spaich EG, Larsen B, Andersen OK. Methods for gait event detection and analysis in ambulatory systems. Med Eng Phys 2010;32:545-52. doi:10.1016/j.medengphy.2010.03.007.

6 [3] Yang M, Zheng H, Wang H, McClean S, Hall J, Harris N. A machine learning approach to assessing

[4] Alaqtash M, Yu H, Brower R, Abdelgawad A, Sarkodie-Gyan T. Application of wearable sensors for human gait analysis using fuzzy computational algorithm. Eng Appl Artif Intell 2011;24:1018-25. doi:10.1016/j.engappai.2011.04.010. clinical problems. J Biomech 2004;37:1869-80. doi:10.1016/j.jbiomech.2004.02.047.

[10] Hanlon M, Anderson R. Real-time gait event detection using wearable sensors. Gait Posture 2009;30:523-7. doi:10.1016/j.gaitpost.2009.07.128. 
multi-channel FES controller based on muscle synergies to support gait rehabilitation after stroke. Front Neurosci 2016;10. doi:10.3389/fnins.2016.00425.

[12] Ferrante S, Ambrosini E, Ravelli P, Guanziroli E, Molteni F, Ferrigno G, et al. A biofeedback cycling training to improve locomotion: a case series study based on gait pattern classification of 153 chronic stroke patients. J Neuroeng Rehabil 2011;8:47. doi:10.1186/1743-0003-8-47.

[13] Balaban B, Tok F. Gait disturbances in patients with stroke. PM R 2014;6:635-42. doi:10.1016/j.pmrj.2013.12.017.

[14] Howell AM, Kobayashi T, Chou TR, Daly W, Orendurff M, Bamberg SJM. A laboratory insole for

[16] Sabatini AM, Martelloni C, Scapellato S, Cavallo F. Assessment of walking features from foot inertial sensing. IEEE Trans Biomed Eng 2005;52:486-94. doi:10.1109/TBME.2004.840727.

[17] Alahakone AU, Senanayake SMNA, Senanayake CM. Smart wearable device for real time gait event detection during running. IEEE Asia-Pacific Conf Circuits Syst Proceedings, APCCAS 2010:612-5. doi:10.1109/APCCAS.2010.5774975.

[18] Azhar MA, Gouwanda D, Gopalai AA. Development of an Intelligent Real - time Heuristic - based Algorithm to Identify Human Gait Events 2014:573-6.

[19] Taborri J, Palermo E, Rossi S, Cappa P. Gait partitioning methods: A systematic review. Sensors (Switzerland) 2016;16:40-2. doi:10.3390/s16010066.

[20] Catalfamo, P, Ghoussayni S, Ewins D. Gait Event Detection on Level Ground and Incline Walking Using a Rate Gyroscope. Sensors 2011;10:5683-702. doi:10.3390/s100605683.

[21] Mannini A, Genovese V, Sabatini AM, Member S. Online Decoding of Hidden Markov Models for Gait Event Detection Using Foot-Mounted Gyroscopes 2014;18:1122-30.

[22] Crea S, Donati M, De Rossi SMM, Oddo CM, Vitiello N. A wireless flexible sensorized insole for gait 
analysis. Sensors (Basel) 2014;14:1073-93. doi:10.3390/s140101073.

[23] Lopez-Meyer P, Fulk GD, Sazonov ES. Automatic detection of temporal gait parameters in poststroke individuals. IEEE Trans Inf Technol Biomed 2011;15:594-601. doi:10.1109/TITB.2011.2112773.

[24] González I, Fontecha J, Hervás R, Bravo J. An Ambulatory System for Gait Monitoring Based on Wireless Sensorized Insoles. Sensors 2015;15:16589-613. doi:10.3390/s150716589.

[25] Lai DTH, Begg RK, Member S. Computational Intelligence in Gait Research : A Perspective on Current Applications and Future Challenges 2009;13:687-702.

[26] Begg R, Kamruzzaman J. A machine learning approach for automated recognition of movement patterns using basic, kinetic and kinematic gait data. J Biomech 2005;38:401-8. doi:10.1016/j.jbiomech.2004.05.002.

[27] Daffertshofer A, Lamoth CJC, Meijer OG, Beek PJ. PCA in studying coordination and variability: a tutorial. Clin Biomech (Bristol, Avon) 2004;19:415-28. doi:10.1016/j.clinbiomech.2004.01.005.

[28] Deluzio KJ, Astephen JL. Biomechanical features of gait waveform data associated with knee osteoarthritis: an application of principal component analysis. Gait Posture 2007;25:86-93. doi:10.1016/j.gaitpost.2006.01.007.

[29] Lee M, Roan M, Smith B. An application of principal component analysis for lower body kinematics between loaded and unloaded walking. J Biomech 2009;42:2226-30. doi:10.1016/j.jbiomech.2009.06.052.

[30] Muniz a MS, Liu H, Lyons KE, Pahwa R, Liu W, Nobre FF, et al. Comparison among probabilistic neural network, support vector machine and logistic regression for evaluating the effect of subthalamic stimulation in Parkinson disease on ground reaction force during gait. J Biomech 2010;43:720-6. doi:10.1016/j.jbiomech.2009.10.018.

[31] Saeys Y, Inza I, Larrañaga P. A review of feature selection techniques in bioinformatics. Bioinformatics 2007;23:2507-17. doi:10.1093/bioinformatics/btm344.

[32] Yang M, Zheng H, Wang H, Mcclean S. Feature Selection and Construction for the Discrimination ofNeurodegenerative Diseases Based on Gait Analysis. 3rd Int Conf Pervasive Comput Technol Healthc 2009.

[33] Zhang J, Lockhart TE, Soangra R. Classifying lower extremity muscle fatigue during walking using 
machine learning and inertial sensors. Ann Biomed Eng 2014;42:600-12. doi:10.1007/s10439-0130917-0.

[34] Lu Y, Boukharouba K, Boonært J, Fleury A, Lecœuche S. Application of an incremental SVM algorithm for on-line human recognition from video surveillance using texture and color features. Neurocomputing 2014;126:132-40. doi:10.1016/j.neucom.2012.08.071.

[35] Martins M, Costa L, Frizera A, Ceres R, Santos C. Hybridization between multi-objective genetic algorithm and support vector machine for feature selection in walker-assisted gait. Comput Methods Programs Biomed 2014;113:736-48. doi:10.1016/j.cmpb.2013.12.005.

[36] Wu J, Wang J, Liu L. Feature extraction via KPCA for classification of gait patterns. Hum Mov Sci

[37] Dillmann U, Holzhoffer C, Johann Y, Bechtel S, Gräber S, Massing C, et al. Principal Component Analysis of gait in Parkinson's disease: relevance of gait velocity. Gait Posture 2014;39:882-7. doi:10.1016/j.gaitpost.2013.11.021.

[38] Badesa FJ, Morales R, Garcia-Aracil N, Sabater JM, Casals A, Zollo L. Auto-adaptive robot-aided therapy using machine learning techniques. Comput Methods Programs Biomed 2014;116:123-30. doi:10.1016/j.cmpb.2013.09.011.

[39] Ekinci M, Aykut M. Human Gait Recognition Based on Kernel PCA using Projections. J Comput Sci Thechnology 2007;22:867-76.

[40] Liang Z, Lee Y. Eigen-Analysis of Nonlinear PCA with Polynomial Kernels. Stat. Anal. Data Min., 2010, p. 1-22.

[41] Pratihar DK, Deb K, Ghosh A. Optimal path and gait generations simultaneously of a six-legged robot using a GA-fuzzy approach. Rob Auton Syst 2002;41:1-20. doi:10.1016/S0921-8890(02)00273-7.

[42] Ardestani MM, Moazen M, Jin Z. Gait modification and optimization using neural network-genetic algorithm approach: Application to knee rehabilitation. Expert Syst Appl 2014;41:7466-77. doi:10.1016/j.eswa.2014.06.034.

[43] Sarbaz Y, Banaie M, Pooyan M, Gharibzadeh S, Towhidkhah F, Jafari A. Modeling the gait of normal and Parkinsonian persons for improving the diagnosis. Neurosci Lett 2012;509:72-5. doi:10.1016/j.neulet.2011.10.002. 
1 [44] Su F-C, Wu W-L. Design and testing of a genetic algorithm neural network in the assessment of gait patterns. Med Eng Phys 2000;22:67-74. doi:10.1016/S1350-4533(00)00011-4.

[45] Daliri MR. Automatic diagnosis of neuro-degenerative diseases using gait dynamics. Measurement 2012;45:1729-34. doi:10.1016/j.measurement.2012.04.013.

[46] Begg RK, Palaniswami M, Member S, Owen B. upport Vector Machines for Automated Gait Classification. IEEE Trans Biomed Eng 2005;52:828-38.

[47] Khandoker AH, Lai DTH, Begg RK, Member S. Wavelet-Based Feature Extraction for Support Vector Machines for Screening Balance Impairments in the Elderly 2007;15:587-97.

[48] Chan H, Yang M, Wang H, Zheng H, McClean S, Sterritt R, et al. Assessing Gait Patterns of Healthy

[53] Asadi H, Dowling R, Yan B, Mitchell P. Machine learning for outcome prediction of acute ischemic

[51] Chau T. A review of analytical techniques for gait data. Part 2: neural network and wavelet methods. Gait Posture 2001;13:102-20. doi:10.1016/S0966-6362(00)00095-3.

[52] Zheng H, Yang M, Wang H, McClean S. Machine Learning and Statistical Approaches to Support the Discrimination of Neuro- degenerative Diseases Based on Gait Analysis. Intell Patient Manag 2009;53:57-70. doi:10.1017/CBO9781107415324.004. stroke post intra-arterial therapy. PLoS One 2014;9:e88225. doi:10.1371/journal.pone.0088225.

[54] Lai DTH, Levinger P, Begg RK, Gilleard WL, Palaniswami M. Automatic recognition of gait patterns exhibiting patellofemoral pain syndrome using a support vector machine approach. IEEE Trans Inf Technol Biomed 2009;13:810-7. doi:10.1109/TITB.2009.2022927.

[55] Lau H, Tong K, Zhu H. Support vector machine for classification of walking conditions of persons after 
stroke with dropped foot. Hum Mov Sci 2009;28:504-14. doi:10.1016/j.humov.2008.12.003.

[56] Hsu C-W, Lin C-J. A comparison of methods for multiclass support vector machines. IEEE Trans Neural Netw 2002;13:415-25. doi:10.1109/72.991427.

[57] Harper PR. A review and comparison of classification algorithms for medical decision making. Health Policy 2005;71:315-31. doi:10.1016/j.healthpol.2004.05.002.

[58] Lee M, Roan M, Smith B, Lockhart TE. Gait analysis to classify external load conditions using linear discriminant analysis. Hum Mov Sci 2009;28:226-35. doi:10.1016/j.humov.2008.10.008.

[59] Kaczmarczyk K, Wit A, Krawczyk M, Zaborski J. Gait classification in post-stroke patients using artificial neural networks. Gait Posture 2009;30:207-10. doi:10.1016/j.gaitpost.2009.04.010.

[60] Chau T. A review of analytical techniques for gait data. Part 1: fuzzy, statistical and fractal methods. Gait Posture 2001;13:49-66. doi:10.1016/S0966-6362(00)00094-1.

[61] López V, Fernández A, Herrera F. On the importance of the validation technique for classification with imbalanced datasets: Addressing covariate shift when data is skewed. Inf Sci (Ny) 2014;257:1-13. doi:10.1016/j.ins.2013.09.038.

[62] Laroche D, Tolambiya a., Morisset C, Maillefert JF, French RM, Ornetti P, et al. A classification study of kinematic gait trajectories in hip osteoarthritis. Comput Biol Med 2014;55:42-8. doi:10.1016/j.compbiomed.2014.09.012.

[63] Mao Y, Saito M, Kanno T, Wei D, City A. Walking Pattern Analysis and SVM Classification Based on Simulated Gaits 2008;1:5069-72.

[64] Dobson F, Morris ME, Baker R, Graham HK. Gait classification in children with cerebral palsy: a systematic review. Gait Posture 2007;25:140-52. doi:10.1016/j.gaitpost.2006.01.003.

[65] Kinsella S, Moran K. Gait pattern categorization of stroke participants with equinus deformity of the foot. Gait Posture 2008;27:144-51. doi:10.1016/j.gaitpost.2007.03.008.

[66] Pärkkä J, Ermes M, Korpipää P, Mäntyjärvi J, Peltola J, Korhonen I. Activity classification using realistic data from wearable sensors. IEEE Trans Inf Technol Biomed 2006;10:119-28. doi:10.1109/TITB.2005.856863.

[67] Novak D, Mihelj M, Munih M. A survey of methods for data fusion and system adaptation using autonomic nervous system responses in physiological computing. Interact Comput 2012;24:154-72. 
doi:10.1016/j.intcom.2012.04.003.

2 [68] Dai Q. A competitive ensemble pruning approach based on cross-validation technique. KnowledgeBased Syst 2013;37:394-414. doi:10.1016/j.knosys.2012.08.024.

4 [69] Kertész-Farkas A, Dhir S, Sonego P, Pacurar M, Netoteia S, Nijveen H, et al. Benchmarking protein classification algorithms via supervised cross-validation. J Biochem Biophys Methods 2008;70:121523. doi:10.1016/j.jbbm.2007.05.011.

[70] Oh SE, Choi A, Mun JH. Prediction of ground reaction forces during gait based on kinematics and a neural network model. J Biomech 2013;46:2372-80. doi:10.1016/j.jbiomech.2013.07.036.

9 [71] Hanson M a., Powell Jr. HC, Barth AT, Lach J, Brandt-Pearce M. Neural Network Gait Classification for On-Body Inertial Sensors. 2009 Sixth Int Work Wearable Implant Body Sens Networks 2009:1816. doi:10.1109/BSN.2009.48.

12 [72] Hsu C, Chang C, Lin C. A Practical Guide to Support Vector Classification. Natl Taiwan Univ 2010;1:116. 